\title{
Dosimetric effects of Onyx embolization on Gamma Knife arteriovenous malformation dose distributions
}

\author{
David J. Schlesinger, $\mathrm{PhD},{ }^{1,2}$ Håkan Nordström, $\mathrm{PhD},{ }^{3}$ Anders Lundin, $\mathrm{MS},{ }^{3} \mathrm{Zhiyuan} \mathrm{Xu}, \mathrm{MD},{ }^{2}$ and \\ Jason P. Sheehan, MD, PhD',2
}

Departments of ${ }^{1}$ Radiation Oncology and ${ }^{2}$ Neurological Surgery, University of Virginia, Charlottesville, Virginia; and ${ }^{3}$ Elekta Instrument AB, Stockholm, Sweden

\begin{abstract}
OBJECTIVE Patients with arteriovenous malformations (AVMs) treated with Gamma Knife radiosurgery (GKRS) subsequent to embolization suffer from elevated local failure rates and differences in adverse radiation effects. Onyx is a common embolic material for AVMs. Onyx is formulated with tantalum, a high atomic number $(Z=73)$ element that has been investigated as a source of dosimetric uncertainty contributing to the less favorable clinical results. However, prior studies have not modeled the complicated anatomical and beam geometries characteristic of GKRS. This study investigated the magnitude of dose perturbation that can occur due to Onyx embolization using clinically realistic anatomical and Gamma Knife beam models.
\end{abstract}

METHODS Leksell GammaPlan (LGP) was used to segment the AVM nidus and areas of Onyx from postcontrast stereotactic MRI for 7 patients treated with GKRS postembolization. The resulting contours, skull surface, and clinically selected dose distributions were exported from LGP in DICOM-RT (Digital Imaging and Communications in Medicine-radiotherapy) format. Isocenter locations and dwell times were recorded from the LGP database. Contours were converted into $3 \mathrm{D}$ mesh representations using commercial and in-house mesh-editing software. The resulting data were imported into a Monte Carlo (MC) dose calculation engine (Pegasos, Elekta Instruments $\mathrm{AB}$ ) with a beam geometry for the Gamma Knife Perfexion. The MC-predicted dose distributions were calculated with Onyx assigned manufacturerreported physical constants (MC-Onyx), and then compared with corresponding distributions in which Onyx was reassigned constants for water (MC-water). Differences in dose metrics were determined, including minimum, maximum, and mean dose to the AVM nidus; selectivity index; and target coverage. Combined differences in dose magnitude and distance to agreement were calculated as 3D Gamma analysis passing rates using tolerance criteria of $0.5 \% / 0.5 \mathrm{~mm}$, $1.0 \% / 1.0 \mathrm{~mm}$, and $3.0 \% / 3.0 \mathrm{~mm}$.

RESULTS Overall, the mean percentage differences in dose metrics for MC-Onyx relative to MC-water were as follows; all data are reported as mean (SD): minimum dose to $\mathrm{AVM}=-0.7 \%(1.4 \%)$, mean dose to $\mathrm{AVM}=0.1 \%(0.2 \%)$, maximum dose to $\mathrm{AVM}=2.9 \%(5.0 \%)$, selectivity $=0.1 \%(0.2 \%)$, and coverage $=-0.0 \%(0.2 \%)$. The mean percentage of voxels passing at each Gamma tolerance were as follows: $99.7 \%(0.1 \%)$ for $3.0 \% / 3.0 \mathrm{~mm}, 98.2 \%(0.7 \%)$ for $1.0 \% / 1.0 \mathrm{~mm}$, and $52.1 \%(4.4 \%)$ for $0.5 \% / 0.5 \mathrm{~mm}$.

CONCLUSIONS Onyx embolization appears to have a detectable effect on the delivered dose distribution. However, the small changes in dose metrics and high Gamma passing rates at $1.0 \% / 1.0 \mathrm{~mm}$ tolerance suggest that these changes are unlikely to be clinically significant. Additional sources of delivery and biological uncertainty should be investigated to determine the root cause of the observed less favorable postembolization GKRS outcomes.

http://thejns.org/doi/abs/10.3171/2016.6.GKS161502

KEY WORDS AVM; stereotactic radiosurgery; embolization; Gamma Knife

$\mathrm{T}$

HE primary goal in the management of cerebral arteriovenous malformations ( $\mathrm{AVMs})$ is to eliminate the risk of intracranial hemorrhage, which is responsible for the most serious neurological complications of the disorder. The risk of hemorrhage in untreated AVMs is estimated to be in the range of $2.2 \%-4.0 \%$ per year, with a total mortality rate due to a hemorrhage in the range of $23 \%-29 \% .4,19,30$ The most effective way to eliminate this

ABBREVIATIONS AVM = arteriovenous malformation; DTA = distance to agreement; GKRS = Gamma Knife radiosurgery; LGP = Leksell GammaPlan; MC = Monte Carlo; NBCA = N-butyl cyanoacrylate; STL = stereolithography.

SUBMITTED June 9, 2016. ACCEPTED June 29, 2016.

INCLUDE WHEN CITING DOI: 10.3171/2016.6.GKS161502. 
risk is by obliteration of the AVM nidus through one or a combination of strategies including microsurgery, radiosurgery, and embolization. . $^{933,40,45,57}$

Stereotactic radiosurgery, particularly Gamma Knife radiosurgery (GKRS), has gained a prominent role in the management of cerebral AVMs due to its high obliteration rate, low complication rate, and minimally invasive nature relative to microsurgery. ${ }^{24,34,46,47}$ Obliteration rates with the Gamma Knife are related to prescription dose; at a prescription dose of $25 \mathrm{~Gy}$, AVM obliteration occurs approximately $60 \%-80 \%$ of the time. The obliteration rate decreases as the prescription dose to the nidus is decreased or the nidus volume is increased. ${ }^{48}$

\section{Embolic Agents and Potential Effects on Delivered Dose Distribution}

Embolization of AVMs is also playing an increasingly important role, often as an adjuvant treatment to radiosurgery or microsurgery, with the goal to reduce the nidal volume of large AVMs and minimize the risks of any intranidal aneurysms and arteriovenous fistulas. ${ }^{1,11,14,15}$

Unfortunately, in a small subset of patients, GKRS fails to result in complete obliteration of the AVM nidus, prolonging the risk of hemorrhage and, in most cases, necessitating retreatment of the AVM. ${ }^{56}$ Several published series report on potential causes for failure in radiosurgical treatment for cerebral AVMs. A common theme is that prior embolization may be an important prognostic factor; however, the specific reasons for this lower obliteration rate remain unclear. ${ }^{10,12,14,20,28,41}$

Historically, the most commonly used agent was $\mathrm{N}$ butyl cyanoacrylate (NBCA), which is a fast-polymerizing liquid adhesive. ${ }^{17,54}$ This agent has been reported to be difficult to use due to unpredictability of the flow and speed of polymerization. ${ }^{53}$ More recently, Onyx (Covidien), a less-adhesive, more slowly polymerizing agent, has gained prominence. Onyx is an ethylene vinyl alcohol copolymer dissolved in dimethyl sulfoxide ${ }^{49,52}$ (Table 1). Onyx comes in 2 basic viscosities: Onyx 18 (18 centistokes) and Onyx 34 (34 centistokes).

The tantalum component of Onyx exists to make the material radio-opaque when injected through a microcatheter under fluoroscopy guidance..$^{53}$ Tantalum is a transition metal with the relatively high atomic number 73 . For comparison, titanium, which is an often-studied interface metal commonly used in biocompatible implants, has atomic number 22 and is considered a "high-Z" material relative to soft tissue (effective $Z=5-8$ ) or bone (effective $Z=14) .{ }^{18}$ Whereas the presence of tantalum is an asset for visualization under fluoroscopy, it is a liability for CT imaging. The high- $\mathrm{Z}$ tantalum causes significant image artifact at typical kilovoltage CT energies (Fig. 1 left). However, investigation has found that Onyx creates a signal void, but little image distortion, on T1-weighted MRI (Fig. 1 right). ${ }^{39}$

To minimize the risk of future bleeding, a vital aspect of AVM radiosurgery is to completely cover the nidus with a minimum biologically effective dose. Even the smallest underdose of the nidus can leave the patient at significant risk. ${ }^{16,43}$ Several studies have proposed that the presence of
TABLE 1. Onyx formulation and material composition (as a percentage of weight)

\begin{tabular}{lcc}
\hline \multicolumn{1}{c}{$\begin{array}{c}\text { Component } \\
\text { Name }\end{array}$} & Purpose & $\begin{array}{c}\text { Weight Composition by } \\
\%, \text { Onyx 18/Onyx 34 }\end{array}$ \\
\hline $\begin{array}{l}\text { Ethylene vinyl alcohol } \\
\text { copolymer }\end{array}$ & Embolic material & $3.2: 4.2$ \\
\hline Dimethyl sulfoxide & $\begin{array}{c}\text { Solvent for delivery } \\
\text { into bloodstream }\end{array}$ & $58.2: 57.6$ \\
\hline Tantalum (Z $=73)$ & $\begin{array}{c}\text { Radiographic } \\
\text { visualization }\end{array}$ & $38.6: 38.2$ \\
\hline
\end{tabular}

high-Z materials such as tantalum (or Lipiodol in the case of NBCA) might distort the delivered radiosurgical dose distribution, potentially causing underdosing of the nidus and preventing subsequent obliteration., 1,21,26,37,44 However, these studies were conducted either with a single treatment beam irradiating from 1 direction, or using simple target geometries. In clinical practice using GKRS, the target is a nidus of intricate morphology, which when embolized has a complex mixture of embolic material and blood. The beam geometry is likewise complex, with a total number of beams $=192 \times$ number of isocenters (for a Perfexion model Gamma Knife assuming no sectors are blocked). ${ }^{23}$ Thus, prior studies may not have adequately modeled the complicated anatomical and beam geometries characteristic of GKRS.

This study investigated the magnitude of dose perturbation that can occur due to Onyx embolization by using clinically realistic anatomical and Gamma Knife beam models and a Monte Carlo (MC) approach. Our hypothesis is that although tantalum is a high $(Z=73)$ atomic number material that can cause dosimetric effects, under realistic clinical geometries used in GKRS, any effects will be minimal and will not significantly perturb the delivered dose distribution.

\section{Methods}

\section{Identification of Patients With AVMs Embolized With Onyx}

We conducted a review of Gamma Knife treatment records at the University of Virginia. We looked for patients with AVMs or dural arteriovenous fistulas that were treated with both GKRS and prior embolization using Onyx between 2007 and 2012. Our search was restricted to patients treated later than July 2007, because these radiosurgery procedures were performed on the Gamma Knife Perfexion and therefore have imaging and treatment plans readily available. Twenty-five patients were identified. Ten patients were randomly selected for inclusion in the study. The clinical treatment plans and stereotactic MR images for each patient were located in Leksell GammaPlan (LGP; version 10.1, Elekta Instrument AB). Three patients were excluded because of our inability to visualize the nidus and/or Onyx on postcontrast MRI, leaving 7 patients in the study. The study was approved by the institutional review board at the University of Virginia. 

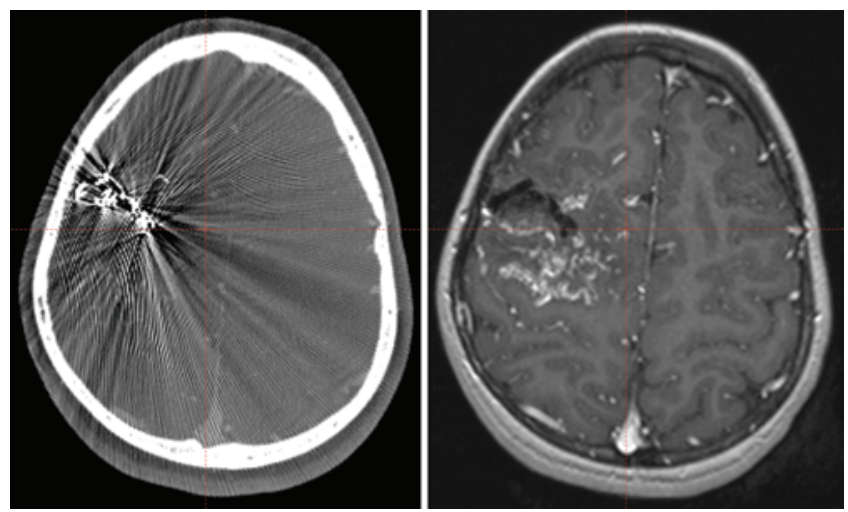

FIG. 1. CT and MR appearances of Onyx embolization. Left: A CT scan of the brain showing extreme artifact caused by the tantalum used to make Onyx radio-opaque. Right: An MR image of the same area of the brain showing Onyx as a signal dropout, along with residual nidus as a mixed pattern of enhancement.

\section{Contouring of AVM Nidus and Onyx}

For each of the 7 patients, contours of the nidus and Onyx embolization were created within LGP on postcontrast stereotactic MRI (3D postcontrast T1-weighted gradient-echo MR; $1.0 \times 1.0 \times 1.3-\mathrm{mm}$ voxels) used for treatment planning. Contours were created by a neurosurgeon, with review by a medical physicist and a neuroradiologist.
The nidus was identified as an area of complicated, mixedcontrast texture, and was correlated to coregistered digital subtraction angiography acquired as part of the treatment planning process. Onyx was identified as a flow void in the general vicinity of the nidus (Fig. 2). ${ }^{39}$

\section{Contour-to-Mesh Conversion Procedure}

The nidus, Onyx, and outer skull contours, as well as the planned dose distributions, were exported in DICOM-RT (Digital Imaging and Communications in Medicine-radiotherapy) format using the functionality built into LGP. The contours were converted into a mesh representation using a multistep procedure (Fig. 3).

\section{Contour Conversion to Mesh Format}

Functionality within 3D Slicer (www.slicer.org) ${ }^{8}$ was used to convert the skull, nidus, and Onyx contour stacks to a $3 \mathrm{D}$ mesh representation (Fig. 4). Once conversion was complete, each mesh was exported from 3D Slicer in stereolithography (STL) file format (3D Systems).

In certain cases, meshes have a very large number of vertices and faces (this is especially true of skull meshes) and take up more memory than the Elekta MC system can handle. A freeware product called MeshLab (ISTI-CNR) was used to perform a decimation of these meshes to reduce the memory footprint while maintaining topological consistency. A quadric edge collapse decimation algo-

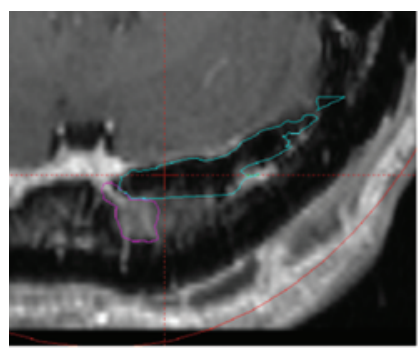

Nidus: $0.40 \mathrm{~cm}^{3}$

Onyx: $3.24 \mathrm{~cm}^{3}$

PI volume: $1.25 \mathrm{~cm}^{3}$

Rx dose: $25 \mathrm{~Gy}->50 \%$

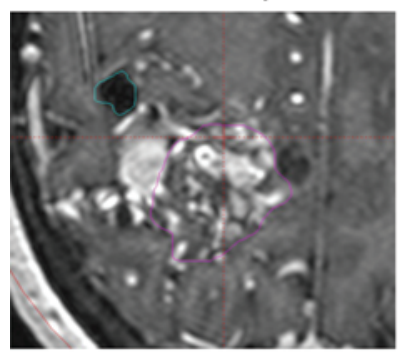

Nidus: $14.29 \mathrm{~cm}^{3}$

Onyx: $0.72 \mathrm{~cm}^{3}$

PI volume: $18.09 \mathrm{~cm}^{3}$

Rx dose: $16 \mathrm{~Gy}->50 \%$

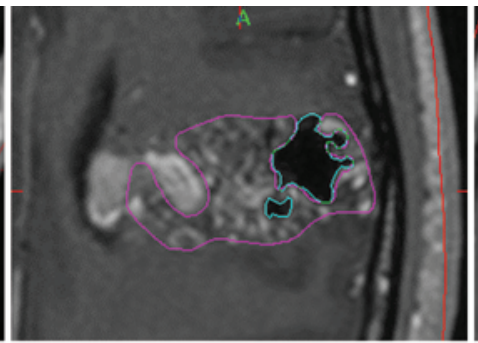

Nidus: $8.23 \mathrm{~cm}^{3}$

Onyx: $2.34 \mathrm{~cm}^{3}$

PI volume: $13.31 \mathrm{~cm}^{3}$

Rx dose : $18 \mathrm{~Gy}->50 \%$
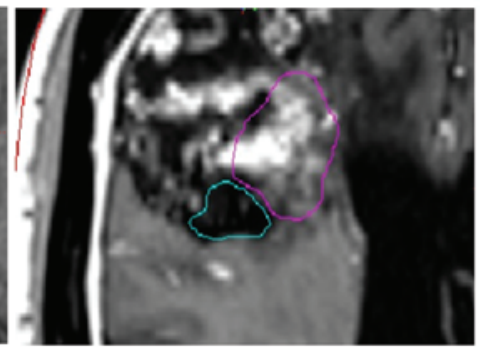

Nidus: $0.21 \mathrm{~cm}^{3}$

Onyx: $0.10 \mathrm{~cm}^{3}$

PI volume: $0.58 \mathrm{~cm}^{3}$

Rx dose: $20 \mathrm{~Gy}->50 \%$

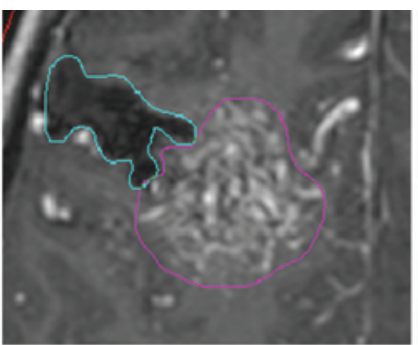

Nidus: $24.43 \mathrm{~cm}^{3}$

Onyx: $3.73 \mathrm{~cm}^{3}$

PI volume: $14.75 \mathrm{~cm}^{3}$

Rx dose: $13.5 \mathrm{~Gy}->50 \%$

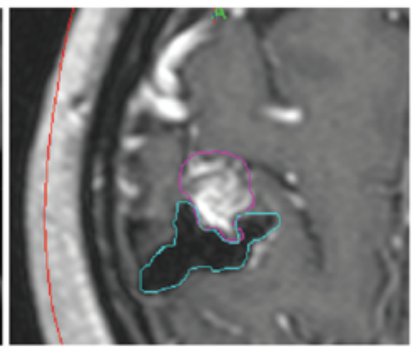

Nidus: $1.67 \mathrm{~cm}^{3}$

Onyx: $2.14 \mathrm{~cm}^{3}$

PI volume: $2.83 \mathrm{~cm}^{3}$

Rx dose: 25 Gy->50\%

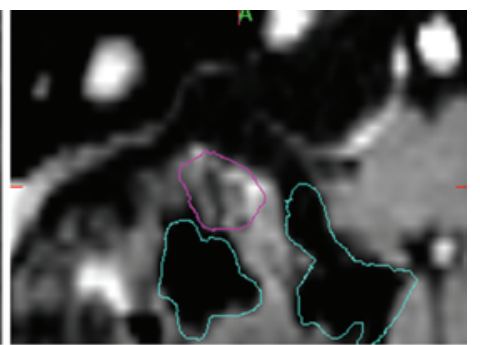

Nidus: $0.29 \mathrm{~cm}^{3}$

Onyx: $5.25 \mathrm{~cm}^{3}$

PI volume: $0.63 \mathrm{~cm}^{3}$

Rx dose: $20 \mathrm{~Gy}->50 \%$

FIG. 2. Representative slices through the MR image of each of the 7 patients included in the study, along with the corresponding nidus (pink) and Onyx (blue) contours. $\mathrm{PI}=$ prescription isodose; $\mathrm{Rx}=$ prescription. 


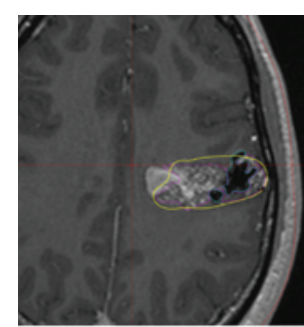

a) DICOM-RT export (LGP)

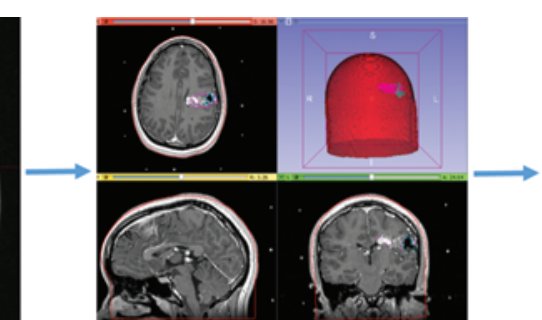

b) Mesh creation from contours (3D Slicer)

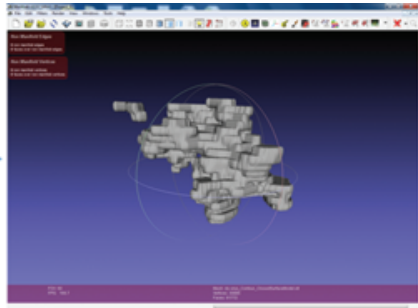

c) Mesh simplification and smoothing (MeshLab)

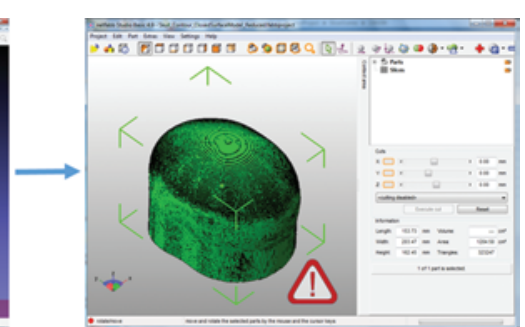

d) Mesh topology repair (NetFabb)
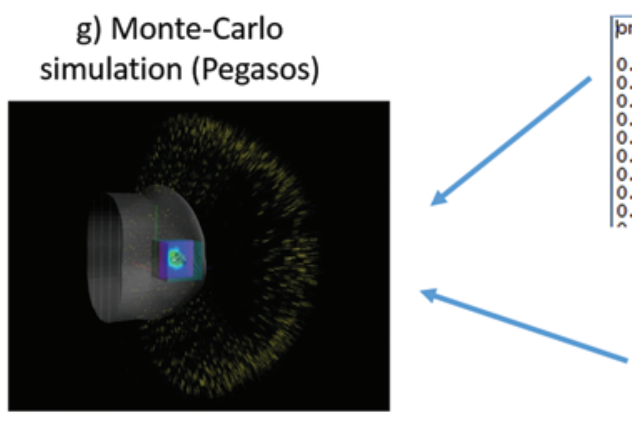
bnyx_contour_closedsurfacemodel m l st? $\begin{array}{lllll}0.107625644282 & 0.0372056714936 & 0.152827923692 & 0.1075861 \\ 0.107625644282 & 0.0372056714936 & 0.152827923692 & 0.1078217\end{array}$ $\begin{array}{llllll}0.107586188228 & 0.0372914190304 & 0.152511278743 & 0.107625\end{array}$ $\begin{array}{lllll}0.107821751817 & 0.0371767155103 & 0.152902782114 & 0.108067 \epsilon \\ 0.107808670556 & 0.0373194165923 & 0.152649355037 & 0.107821\end{array}$ $\begin{array}{lllll}0.107808670556 & 0.0373194165923 & 0.152649355037 & 0.1078217 \\ 0.108067698169 & 0.0371668642842 & 0.152893580337 & 0.1083064\end{array}$ $\begin{array}{lllll}0.108067698169 & 0.0371668642842 & 0.152893580337 & 0.1083064 \\ 0.108060687305 & 0.0373101510174 & 0.152659832547 & 0.108067 \epsilon \\ 0.108306407068 & 0.0371712258307 & 0.152878711156 & 0.108547\end{array}$ $\begin{array}{llll}0.108306407068 & 0.0371712258307 & 0.152878711156 & 0.108547 \varepsilon \\ 0.108303022548 & 0.0373086582354 & 0.152639580936 & 0.1083064\end{array}$

e) Conversion to raw triangle format

$$
A_{\text {multi }}=\left(\begin{array}{cccc}
F_{11} \Delta r & F_{12} \Delta c & \frac{T_{1}^{1}-T_{i}^{N}}{1-N} & T_{1}^{1} \\
F_{21} \Delta r & F_{22} \Delta c & \frac{T_{2}^{1}-T_{2}^{N}}{1-N} & T_{2}^{1} \\
F_{31} \Delta r & F_{32} \Delta c & \frac{T_{3}^{1}-T_{3}^{N}}{1-N} & T_{3}^{1} \\
0 & 0 & 0 & 1
\end{array}\right) \begin{gathered}
\text { f) Stereotactic to } \\
\text { DICOM coordinate } \\
\text { transform (from LGP) }
\end{gathered}
$$

FIG. 3. Procedure for exporting, processing, and converting patient data for subsequent MC simulation. a: Dose and contour export from LGP. b: Mesh creation from contours. c: Mesh simplification and smoothing. d: Mesh topology repair to ensure closed surfaces. e: Mesh conversion to raw triangle format. f: Extraction of transform between stereotactic to imaging coordinates. g: MC simulation.

rithm ${ }^{13}$ within MeshLab was applied to reduce the number of faces by a factor of 10 .

Meshes created with 3D Slicer have terracing artifacts due to the fact that they were created from contour stacks, with 1 contour per slice, and MR slice thicknesses that are of a non-negligible thickness. A smoothing step was thus used to diminish the terracing artifact on nidus and Onyx meshes. ${ }^{51}$

Finally, a second postprocessing step was applied that identifies and repairs meshes to ensure topological closure, which is a requirement for the subsequent $\mathrm{MC}$ analysis. For this step, a commercial product called netfabb (netfabb $\mathrm{GmbH}$ ) was used. Meshes in STL format are imported into netfabb. The software then analyzes the meshes and indicates whether there are defects to be corrected; if so, it applies the corrections.

Completed meshes were re-exported into STL file format and converted into a raw, American Standard Code for Information Interchange (ASCII)-triangle format accepted by the Elekta MC system, using custom software created in the Python programming language.

\section{Coordinate Transformation Determination}

The MC analysis requires knowledge of the transformation between the stereotactic coordinate space used by the Gamma Knife planning system and the imaging (DICOM) coordinate space. This transformation information is stored in $4 \times 4$ matrix form in the Gamma Knife treatment planning system and was extracted using a custom structured query language (SQL) query.

\section{Monte Carlo Analysis}

The completed skull, Onyx, and nidus meshes, as well as the coordinate transformation matrix, were used as inputs into the subsequent MC simulations. The MC simulations were performed using a calculation engine developed at the manufacturer (Pegasos, Elekta Instrument $\mathrm{AB})$ and an associated geometry interface (Hermes, Elekta Instrument AB) (Fig. 5). Predicted radiosurgical dose distributions in the presence of Onyx (MC-Onyx) were obtained by MC simulation assuming physical constants of water for brain and nidus structures, and manufacturerreported physical constants of Onyx for the Onyx contour. These were compared with the dose distributions obtained by setting all structures to the physical constants for water (MC-water), which are similar to the assumptions used by the TMR 10-based treatment algorithm in LGP. ${ }^{55}$

The dose distributions MC-Onyx and MC-water were compared via a variety of dose metrics, including minimum/mean/maximum dose to the nidus, prescription isodose volume, selectivity index $\left(\mathrm{TV}_{\mathrm{PIV}} / \mathrm{PIV}\right)$, coverage index $\left(\mathrm{TV}_{\mathrm{PIV}} / \mathrm{TV}\right)$, and gradient index $\left(\mathrm{PIV}_{\text {half }} / \mathrm{PIV}\right)$, where PIV is the prescription isodose volume, $\mathrm{TV}_{\mathrm{PIV}}$ is the volume of nidus covered by the prescription isodose volume, and PIV half is the volume of the isodose surface that is onehalf of the prescription isodose. ${ }^{31,32}$ All dose metrics were calculated in terms of percentage isodoses (i.e., percentage of maximum dose). As a gross measure of the overall dosimetric difference between MC-Onyx and MC-water, 3D local Gamma passing rates were determined for 3.0 $\mathrm{mm} / 3.0 \%, 1.0 \mathrm{~mm} / 1.0 \%$, and $0.5 \mathrm{~mm} / 0.5 \%$ passing crite- 


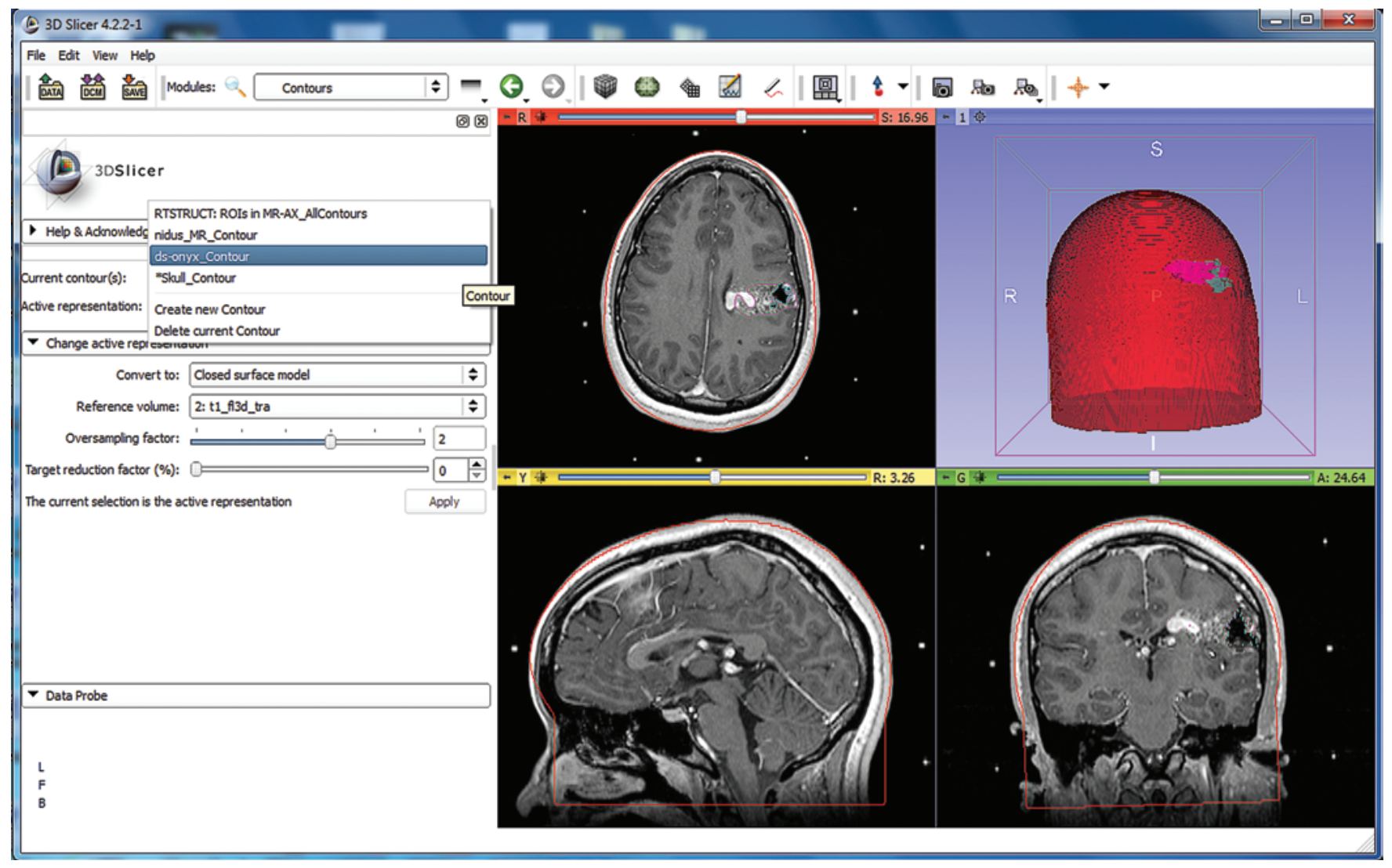

FIG. 4. Conversion of contour stacks into a 3D mesh representation using 3D Slicer.

ria. ${ }^{25}$ MATLAB (version R2015a, MathWorks) was used for analysis of all dose metrics.

\section{Results}

Overall, MC determined that dosimetric differences between MC-Onyx and MC-water were small (Table 2). The largest difference in dose metrics was the maximum dose to the nidus, with a mean (standard deviation) difference of $2.9 \%(5.0 \%)$. All other dose-metric differences were less than $1.0 \%$. The Gamma passing rates were $52.1 \%$ (4.4\%), $98.2 \%(0.7 \%)$, and $99.7 \%(0.1 \%)$ for $0.5 \% / 0.5 \mathrm{~mm}, 1.0 \% / 1.0$ $\mathrm{mm}$, and $3.0 \% / 3.0 \mathrm{~mm}$, respectively (Table 3 ). Close inspection of the results in some cases shows some minor shifts in isodose curves, especially at higher isodose levels (i.e., 70\%-90\%), between MC-Onyx and MC-water (Fig. 6).

\section{Discussion}

Our results suggest that there are detectable differences in dose distribution caused by the presence of Onyx. However, the magnitude and location of the differences suggest that they are not likely to be clinically significant in terms of obliteration probability. Close inspection of the MC-calculated distributions for MC-Onyx and MC-water show that many of the differences are in high-isodose regions near or inside of the Onyx. This is further supported by the somewhat larger difference in maximum nidus dose between MC-Onyx and MC-water (2.9\% mean dif- ference) compared with the other dose metrics, which are all less than $1.0 \%$ mean difference. It should be noted that the maximum dose to the nidus is a point dose that can be highly sensitive to effects such as calculation grid alignment and resolution $(0.5 \mathrm{~mm}$ in this study).

Our study applies the concept of Gamma analysis to provide a measure of the global match between 2 dose distributions by combining a distance to agreement (DTA) criterion and a voxel-by-voxel dose-difference criterion..$^{25}$ A given voxel "fails" the Gamma analysis if it lies outside of the specified DTA and/or dose-difference criterion. The percentage of voxels that fail the Gamma analysis can be used as a global measure of the similarity of 2 distributions. Our results show a sharp rise in Gamma passing rates, from a mean of $52.1 \%$ at the $0.5 \mathrm{~mm} / 0.5 \%$ (DTA/ dose) criterion to $98.2 \%$ at $1.0 \mathrm{~mm} / 1.0 \%$. These results suggest that if one considers the approximate overall uncertainty of a radiosurgery procedure (i.e., approximately $1.0 \mathrm{~mm}$ uncertainty), then the difference between MC-Onyx and MC-water distributions are not likely to be clinically significant. We believe that the smaller passing rates at the more stringent $0.5 \mathrm{~mm} / 0.5 \%$ criterion probably reflect contouring and grid resolution uncertainties, as well as distortions in dose caused by the Onyx embolization.

\section{Prior Work}

It has long been recognized that a significant amount of scattered radiation can result from the introduction of 

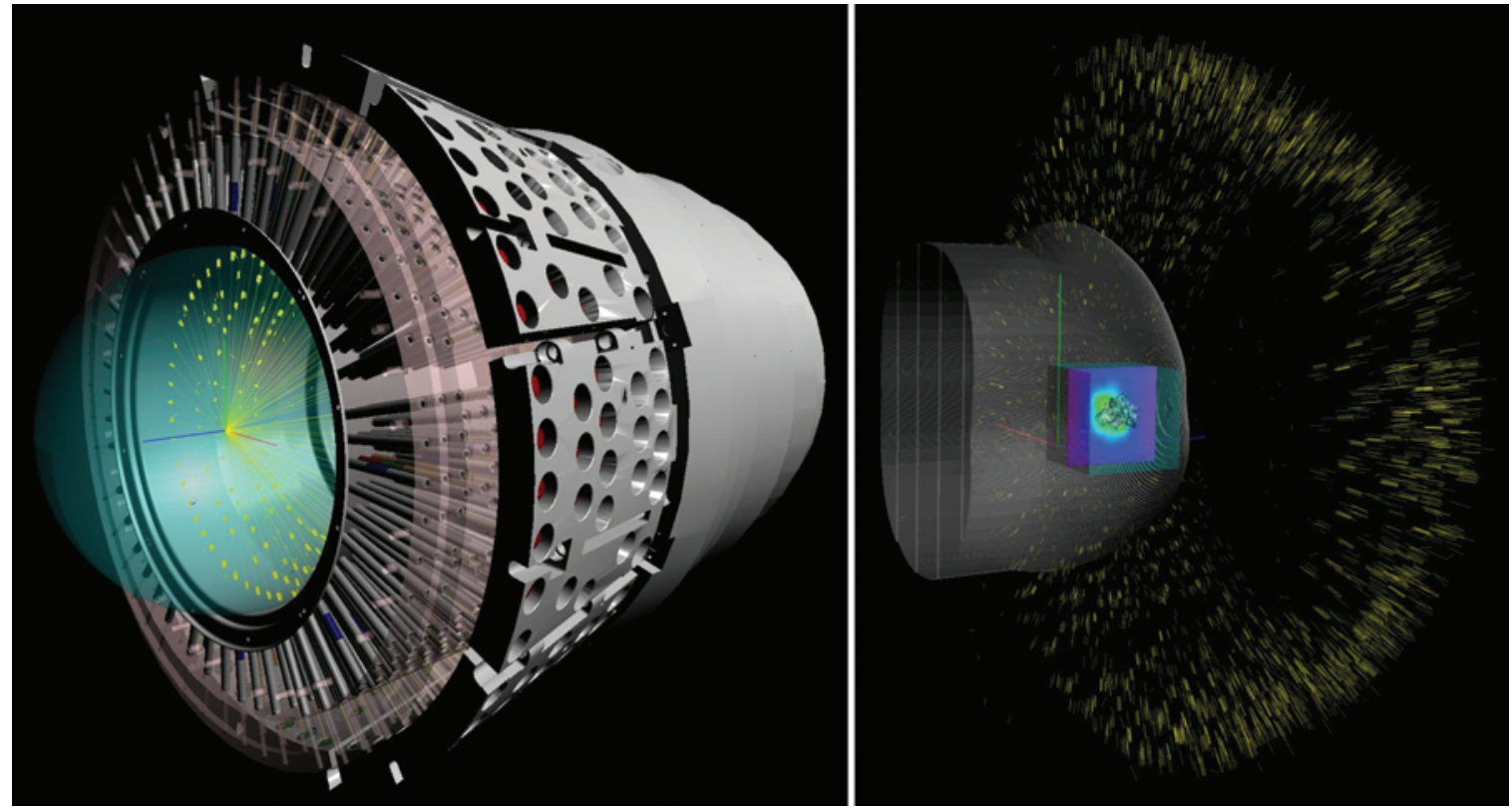

FIG. 5. MC simulation of GKRS for embolized AVMs. Left: Gamma Knife Perfexion geometry model used for phase-space generation (Hermes, Elekta Instrument AB). Right: MC simulation for 1 patient showing AVM nidus and Onyx within LGP dose matrix along with sample simulated particle trajectories.

high-atomic-number (high-Z) materials into a megavoltage photon beam. ${ }^{6,42}$ This has also been shown to be true at low-Z-high-Z interfaces, such as that between tissue and metal implants. $7,27,29,36,38,50$

Several investigators have attempted to quantify the probable effect that the high-Z components of embolic materials would have on the delivered dose distribution. Andrade-Souza et al. conducted a study involving NBCA using a single 5-MV photon beam irradiating a block of solid water with embedded wells of embolic material, sandwiched with radiochromic film in a solid-water phantom. They found a 10\%-15\% dose reduction downstream of the embolic material relative to solid water, which varied with the concentration of Lipiodol. ${ }^{2}$ Roberts et al. performed a

TABLE 2. MC-determined dosimetric differences between MC-Onyx and MC-water*

\begin{tabular}{lc}
\hline \multicolumn{1}{c}{ Dosimetric Parameter } & $\begin{array}{c}\text { \% Difference MC-Water vs } \\
\text { MC-Onyx, Mean (SD) }\end{array}$ \\
\hline Nidus, min dose & $-0.7(1.4)$ \\
\hline Nidus, mean dose & $0.1(0.2)$ \\
\hline Nidus, max dose & $2.9(5.0)$ \\
\hline Rx isodose vol & $-0.1(0.3)$ \\
\hline Coverage $\left(\mathrm{TV}_{\mathrm{PIV}} / \mathrm{TV}\right)$ & $-0.0(0.2)$ \\
\hline Selectivity $\left(\mathrm{TV}_{\mathrm{PIV}} / \mathrm{PIV}\right)$ & $0.1(0.2)$ \\
\hline Gradient index (PIV $/$ half $/ \mathrm{PIV})$ & $-0.0(1.5)$ \\
\hline
\end{tabular}

PIV = prescription isodose volume; $\mathrm{PIV}_{\text {half }}=$ volume of the isodose surface that is one-half of the prescription isodose; $\mathrm{Rx}=$ prescription; $\mathrm{TV}_{\mathrm{PIV}}=$ volume of nidus covered by the prescription isodose volume.

* MC-water is the reference. Coverage, selectivity, and gradient index calculations based on Paddick (2000) and Paddick and Lippitz (2006). similar set of measurements at 6-MV and 16-MV beam energies. At $6 \mathrm{MV}$, they found $97 \%$ beam transmission relative to water, and a $1 \%$ interface enhancement. ${ }^{37} \mathrm{Mam}-$ alui-Hunter et al. created a simplified model of a Gamma Knife beam geometry using ray tracing. They estimated the effective linear attenuation coefficient of Onyx at ${ }^{60} \mathrm{Co}$ energy from observed CT Hounsfield numbers at 120- to $140-\mathrm{kV}$ energies. At ${ }^{60} \mathrm{Co}$ energies, they found a $0.2 \%$ dose reduction per beam and a $<0.01 \%-0.2 \%$ overall reduction in dose at the center of an Onyx target. ${ }^{26}$ Labby et al. calculated linear attenuation coefficients for NBCA with added Lipiodol, and with and without added tantalum. They found that at 6-MV photon energies, the dosimetric error would remain $<1 \%$ for emboli up to $1.1-\mathrm{cm}$ thick..$^{21}$

The majority of these interface studies used a unidirectional experimental setup. A single beam (typically from a linear accelerator or ${ }^{60} \mathrm{Co}$ unit) was used to perpendicularly irradiate the interface and measure the dose distortion. However, GKRS uses a large number of cross-firing beams to help spread incident energy and achieve a characteristically steep dose gradient. The results of our study show that although localized dose effects can occur (especially within regions of Onyx), the high Gamma Index passing

TABLE 3. Voxel passing rates of 3D Gamma analysis*

\begin{tabular}{cc}
\hline $\begin{array}{c}\text { Gamma Passing Rate Criteria } \\
\text { (dose difference [\%]/DTA [mm]) }\end{array}$ & $\begin{array}{c}\text { \% Passing Rate, } \\
\text { Mean (SD) }\end{array}$ \\
\hline $0.5: 0.5$ & $52.1(4.4)$ \\
\hline $1.0: 1.0$ & $98.2(0.7)$ \\
\hline $3.0: 3.0$ & $99.7(0.1)$ \\
\hline
\end{tabular}

* Comparison between MC-Onyx and MC-water dose distributions. 

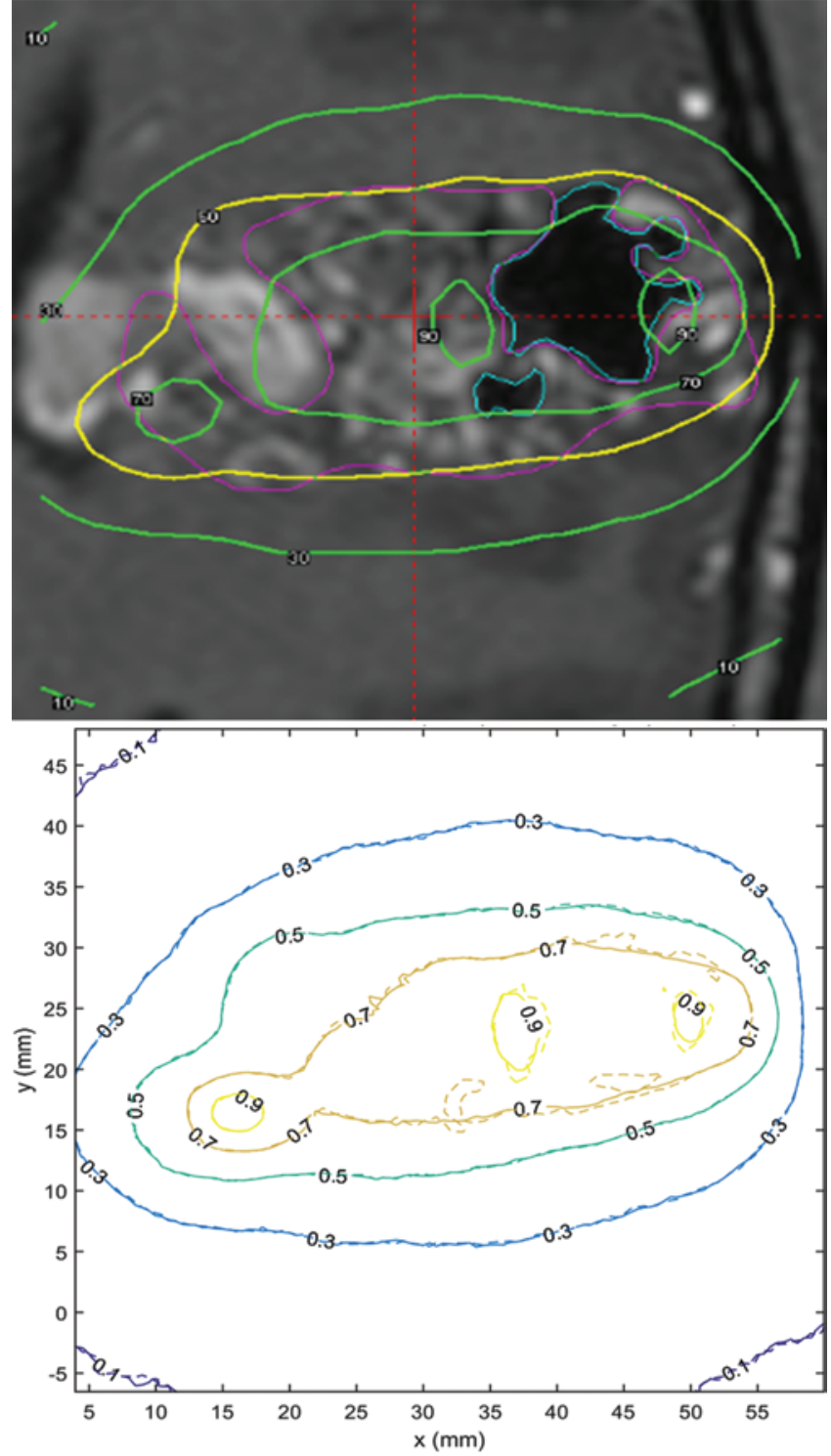

FIG. 6. Example case showing differences between MC-Onyx and MC-water dose distributions. Upper: LGP-calculated dose distribution overlaid on T1-weighted MR image with Onyx (b/ue) and nidus (pink) contoured. Lower: MC-water (solid lines) and MC-Onyx (dotted lines) isodose curves from an axial plane corresponding to the slice in the upper panel. The curves show minor areas of disagreement, mainly at high isodose lines (such as the $70 \%$ isodose line).

rate at traditional radiosurgery tolerances $(98.2 \%$ passing at $1.0 \mathrm{~mm} / 1.0 \%$ tolerance) and the similar selectivity and coverage metrics (mean differences of $0.1 \%$ and $-0.0 \%$, respectively) suggest that these effects tend to be equalized over a typical Gamma Knife treatment geometry and are not likely to be clinically significant. These findings support the conclusions of Mamalui-Hunter et al., who similarly investigated a Gamma Knife beam geometry. ${ }^{26}$

\section{Alternative Causes of Poor Stereotactic Radiosurgery Results}

Pollock et al. found that incomplete angiographic defi- nition of the nidus was the most common reason for incomplete obliteration, with recanalization of prior embolization playing an important role. ${ }^{35}$ Gallina et al. similarly cited inaccurate target definition and recanalization of a previously embolized nidus, as did Kwon et al. ${ }^{12,20}$ Bauer et al. presented a case study demonstrating volume loss within an Onyx embolus and subsequent nidus recanalization. ${ }^{3}$ Flickinger et al. concluded that along with marginal dose, target definition significantly affects outcome, and this is made more difficult by prior embolization..$^{10}$ Buis et al. investigated the effect of intraobserver variation in target definition on outcome and found that patients with prior embolization had larger variations in target delineation. ${ }^{5}$

Other factors cited by these studies as causes of treatment failure include "radiobiological resistance," incomplete nidus definition due to obscuring hematomas, and intentional partial radiation of the target. However, it should be noted that not all studies investigating postembolization radiosurgery have found a negative effect on the probability of obliteration. A study published by our own institution investigated the clinical effect of embolization on subsequent stereotactic radiosurgery obliteration probability and found no statistically significant difference, albeit with a relatively small patient cohort. ${ }^{22}$

\section{Study Limitations}

Limitations of our study include a small number of patients, uncontrolled variability in contour morphology and nidus/Onyx distance, contouring uncertainty of both the nidus and Onyx, and uncertainty in the clinically achieved concentration of tantalum within the nidus (i.e., the concentration of tantalum can vary depending on the Onyx/ blood mixture achieved upon injection). We believe that a strength of our approach is the use of actual clinical data, including the clinical morphology of the AVM nidus and Onyx and a clinical beam setup, when making comparisons. Our results thus far support the prior results of Mamalui-Hunter et al., who used a similar Gamma Knife beam geometry and a more regular Onyx target. ${ }^{26}$ Further work will include simulations on a larger patient cohort, determination of the dependence of any dose perturbation on the concentration of tantalum in the sample, and correlation of dose metrics to the probability of nidus obliteration.

\section{Conclusions}

The high-Z tantalum component of Onyx appears to have localized, detectable effects on the delivered dose distribution as calculated by MC simulation. However, the small changes in dose metrics and high Gamma passing rates at $1.0 \% / 1.0 \mathrm{~mm}$ tolerance suggest that these changes are unlikely to be clinically significant to the dose distribution as a whole. Additional sources of delivery and biological uncertainty should be investigated to determine the root cause of the observed less favorable postembolization GKRS outcomes.

\section{Acknowledgments}

We thank Emin Faruk Kececi, $\mathrm{PhD}$, for his work on aspects of 
this project not directly related to this manuscript, including phantom design and construction.

\section{References}

1. Andrade-Souza YM, Ramani M, Beachey DJ, Scora D, Tsao MN, terBrugge K, et al: Liquid embolisation material reduces the delivered radiation dose: a physical experiment. Acta Neurochir (Wien) 150:161-164, 2008

2. Andrade-Souza YM, Ramani M, Scora D, Tsao MN, terBrugge K, Schwartz ML: Embolization before radiosurgery reduces the obliteration rate of arteriovenous malformations. Neurosurgery 60:443-452, 2007

3. Bauer AM, Bain MD, Rasmussen PA: Onyx resorbtion with AVM recanalization after complete AVM obliteration. Int Neuroradiol 21:351-356, 2015

4. Brown RD Jr, Wiebers DO, Forbes G, O'Fallon WM, Piepgras DG, Marsh WR, et al: The natural history of unruptured intracranial arteriovenous malformations. J Neurosurg 68:352-357, 1988

5. Buis DR, Lagerwaard FJ, Barkhof F, Dirven CMF, Lycklama GJ, Meijer OWM, et al: Stereotactic radiosurgery for brain AVMs: role of interobserver variation in target definition on digital subtraction angiography. Int J Radiat Oncol Biol Phys 62:246-252, 2005

6. Dutreix J, Bernard M: Dosimetry at interfaces for high energy X and gamma rays. Br J Radiol 39:205-210, 1966

7. Farahani M, Eichmiller FC, McLaughlin WL: Measurement of absorbed doses near metal and dental material interfaces irradiated by x- and gamma-ray therapy beams. Phys Med Biol 35:369-385, 1990

8. Fedorov A, Beichel R, Kalpathy-Cramer J, Finet J, FillionRobin JC, Pujol S, et al: 3D Slicer as an image computing platform for the Quantitative Imaging Network. Magn Reson Imaging 30:1323-1341, 2012

9. Fernández-Melo R, López-Flores G, Cruz-García O, JordánGonzález J, Felipe-Morán A, Benavides-Barbosa J, et al: [Modes of treatment for arteriovenous malformations of the brain.] Rev Neurol 37:967-975, 2003 (Span)

10. Flickinger JC, Kondziolka D, Maitz AH, Lunsford LD: An analysis of the dose-response for arteriovenous malformation radiosurgery and other factors affecting obliteration. Radiother Oncol 63:347-354, 2002

11. Gailloud P: Endovascular treatment of cerebral arteriovenous malformations. Tech Vasc Interv Radiol 8:118-128, 2005

12. Gallina P, Nataf F, Merienne L, Schlienger M, Lefkopoulos D, Roux FX: [Retrospective analysis of failures in radiosurgery treatment of cerebral arteriovenous malformations.] Neurochirurgie 47:311-317, 2001 (Fr)

13. Garland M, Heckbert PS: Surface simplification using quadric error metrics, in Proceedings of the 24th Annual Conference on Computer Graphics and Interactive Techniques. New York: ACM Press/Addison-Wesley Publishing Co., 1997, pp 209-216

14. Gobin YP, Laurent A, Merienne L, Schlienger M, Aymard A, Houdart E, et al: Treatment of brain arteriovenous malformations by embolization and radiosurgery. $\mathbf{J}$ Neurosurg 85:19-28, 1996

15. Goto K, Uda K, Ogata N: Embolization of cerebral arteriovenous malformations (AVMs) - material selection, improved technique, and tactics in the initial therapy of cerebral AVMs. Neurol Med Chir (Tokyo) 38 Suppl:193-199, 1998

16. Guo WY, Karlsson B, Ericson K, Lindqvist M: Even the smallest remnant of an AVM constitutes a risk of further bleeding. Case report. Acta Neurochir (Wien) 121:212-215, 1993

17. Jafar JJ, Davis AJ, Berenstein A, Choi IS, Kupersmith MJ: The effect of embolization with N-butyl cyanoacrylate prior to surgical resection of cerebral arteriovenous malformations. J Neurosurg 78:60-69, 1993
18. Kahn FM: The Physics of Radiation Therapy. Baltimore: Williams \& Wilkins, 1984

19. Karlsson B, Lindquist C, Johansson A, Steiner L: Annual risk for the first hemorrhage from untreated cerebral arteriovenous malformations. Minim Invasive Neurosurg 40:40-46, 1997

20. Kwon Y, Jeon SR, Kim JH, Lee JK, Ra DS, Lee DJ, et al: Analysis of the causes of treatment failure in Gamma Knife radiosurgery for intracranial arteriovenous malformations. $\mathbf{J}$ Neurosurg 93 (Suppl 3):104-106, 2000

21. Labby ZE, Chaudhary N, Gemmete JJ, Pandey AS, Roberts DA: Dosimetric measurements of an n-butyl cyanoacrylate embolization material for arteriovenous malformations. Med Phys 42:1739-1744, 2015

22. Lee CC, Chen CJ, Ball B, Schlesinger D, Xu Z, Yen CP, et al: Stereotactic radiosurgery for arteriovenous malformations after Onyx embolization: a case-control study. J Neurosurg 123:126-135, 2015

23. Lindquist C, Paddick I: The Leksell Gamma Knife Perfexion and comparisons with its predecessors. Neurosurgery 61 (3 Suppl):130-141, 2007

24. Lindquist C, Steiner L: Stereotactic radiosurgical treatment of arteriovenous malformations, in Lunsford LD (ed): Modern Stereotactic Neurosurgery. Boston: Martinus Nijhoff, 1988, pp 491-505

25. Low DA, Harms WB, Mutic S, Purdy JA: A technique for the quantitative evaluation of dose distributions. Med Phys 25:656-661, 1998

26. Mamalui-Hunter M, Jiang T, Rich KM, Derdeyn CP, Drzymala RE: Effect of liquid embolic agents on Gamma Knife surgery dosimetry for arteriovenous malformations. Clinical article. J Neurosurg 115:364-370, 2011

27. Mian TA, Van Putten MC Jr, Kramer DC, Jacob RF, Boyer AL: Backscatter radiation at bone-titanium interface from high-energy X and gamma rays. Int J Radiat Oncol Biol Phys 13:1943-1947, 1987

28. Miyawaki L, Dowd C, Wara W, Goldsmith B, Albright N, Gutin P, et al: Five year results of LINAC radiosurgery for arteriovenous malformations: outcome for large AVMS. Int J Radiat Oncol Biol Phys 44:1089-1106, 1999

29. Niroomand-Rad A, Razavi R, Thobejane S, Harter KW: Radiation dose perturbation at tissue-titanium dental interfaces in head and neck cancer patients. Int J Radiat Oncol Biol Phys 34:475-480, 1996

30. Ondra SL, Troupp H, George ED, Schwab K: The natural history of symptomatic arteriovenous malformations of the brain: a 24-year follow-up assessment. J Neurosurg 73:387391, 1990

31. Paddick I: A simple scoring ratio to index the conformity of radiosurgical treatment plans. Technical note. J Neurosurg 93 (Suppl 3):219-222, 2000

32. Paddick I, Lippitz B: A simple dose gradient measurement tool to complement the conformity index. J Neurosurg 105 Suppl:194-201, 2006

33. Pollock BE, Flickinger JC, Lunsford LD, Bissonette DJ, Kondziolka D: Hemorrhage risk after stereotactic radiosurgery of cerebral arteriovenous malformations. Neurosurgery 38:652-661, 1996

34. Pollock BE, Gorman DA, Coffey RJ: Patient outcomes after arteriovenous malformation radiosurgical management: results based on a 5- to 14-year follow-up study. Neurosurgery 52:1291-1297, 2003

35. Pollock BE, Kondziolka D, Lunsford LD, Bissonette D, Flickinger JC: Repeat stereotactic radiosurgery of arteriovenous malformations: factors associated with incomplete obliteration. Neurosurgery 38:318-324, 1996

36. Ravikumar M, Ravichandran R, Sathiyan S, Supe SS: Backscattered dose perturbation effects at metallic interfaces irradiated by high-energy X-and gamma-ray therapeutic beams. Strahlenther Onkol 180:173-178, 2004 
37. Roberts DA, Balter JM, Chaudhary N, Gemmete JJ, Pandey AS: Dosimetric measurements of Onyx embolization material for stereotactic radiosurgery. Med Phys 39:6672-6681, 2012

38. Rosengren B, Wulff L, Carlsson E, Carlsson J, Montelius A, Russell K, et al: Backscatter radiation at tissue-titanium interfaces. Analyses of biological effects from ${ }^{60} \mathrm{Co}$ and protons. Acta Oncol 30:859-866, 1991

39. Saatci I, Cekirge HS, Ciceri EF, Mawad ME, Pamuk AG, Besim A: CT and MR imaging findings and their implications in the follow-up of patients with intracranial aneurysms treated with endosaccular occlusion with onyx. AJNR Am J Neuroradiol 24:567-578, 2003

40. Schaller C, Schramm J: Microsurgical results for small arteriovenous malformations accessible for radiosurgical or embolization treatment. Neurosurgery 40:664-674, 1997

41. Schlienger M, Atlan D, Lefkopoulos D, Merienne L, Touboul E, Missir O, et al: Linac radiosurgery for cerebral arteriovenous malformations: results in 169 patients. Int J Radiat Oncol Biol Phys 46:1135-1142, 2000

42. Scrimger JW: Backscatter from high atomic number materials in high energy photon beams. Radiology 124:815-817, 1977

43. Shin M, Kawahara N, Maruyama K, Tago M, Ueki K, Kirino T: Risk of hemorrhage from an arteriovenous malformation confirmed to have been obliterated on angiography after stereotactic radiosurgery. J Neurosurg 102:842-846, 2005

44. Shtraus N, Schifter D, Corn BW, Maimon S, Alani S, Frolov $\mathrm{V}$, et al: Radiosurgical treatment planning of AVM following embolization with Onyx: possible dosage error in treatment planning can be averted. J Neurooncol 98:271-276, 2010

45. Söderman M, Andersson T, Karlsson B, Wallace MC, Edner G: Management of patients with brain arteriovenous malformations. Eur J Radiol 46:195-205, 2003

46. Steiner L, Lindquist C: Radiosurgery in cerebral arteriovenous malformation, in Tasker RR (ed): Neurosurgery: State of the Art Review. Stereotactic Surgery. Philadelphia: Hanley \& Belfus, 1987, pp 329-336

47. Steiner L, Lindquist C, Adler JR, Torner JC, Alves W, Steiner $\mathrm{M}$ : Clinical outcome of radiosurgery for cerebral arteriovenous malformations. J Neurosurg 77:1-8, 1992

48. Steiner L, Sheehan J, Lindquist C, Stroila M, Steiner M: Gamma surgery in cerebral vascular lesions, malformations, tumors, and functional disorders, in Schmidek HH, Roberts DW (eds): Schmidek \& Sweet Operative Neurosurgical Techniques: Indications, Methods, and Results, ed 5. Philadelphia: Saunders, 2006, Vol 1, pp 530-576

49. Taki W, Yonekawa Y, Iwata H, Uno A, Yamashita K, Amemiya H: A new liquid material for embolization of arteriovenous malformations. AJNR Am J Neuroradiol 11:163-168, 1990

50. Tatcher M, Kuten A, Helman J, Laufer D: Perturbation of cobalt 60 radiation doses by metal objects implanted during oral and maxillofacial surgery. J Oral Maxillofac Surg 42:108-110, 1984
51. Taubin G: Curve and surface smoothing without shrinkage, in Fifth International Conference on Computer Vision. New York: IEEE, 1995, pp 852-857

52. Terada T, Nakamura Y, Nakai K, Tsuura M, Nishiguchi T, Hayashi S, et al: Embolization of arteriovenous malformations with peripheral aneurysms using ethylene vinyl alcohol copolymer. Report of three cases. J Neurosurg 75:655-660, 1991

53. van Rooij WJ, Sluzewski M, Beute GN: Brain AVM embolization with Onyx. AJNR Am J Neuroradiol 28:172-178, 2007

54. Wallace RC, Flom RA, Khayata MH, Dean BL, McKenzie J, Rand JC, et al: The safety and effectiveness of brain arteriovenous malformation embolization using acrylic and particles: the experiences of a single institution. Neurosurgery 37:606-618, 1995

55. Xu AY, Bhatnagar J, Bednarz G, Niranjan A, Kondziolka D, Flickinger J, et al: Gamma Knife radiosurgery with CT image-based dose calculation. J Appl Clin Med Phys 16:5530, 2015

56. Yen CP, Varady P, Sheehan J, Steiner M, Steiner L: Subtotal obliteration of cerebral arteriovenous malformations after Gamma Knife surgery. J Neurosurg 106:361-369, 2007

57. Yoshimoto T, Kayama T, Suzuki J: Treatment of cerebral arteriovenous malformation. Neurosurg Rev 9:279-285, 1986

\section{Disclosures}

This work was funded by a grant from Elekta Instrument AB. Mr. Lundin and Dr. Nordström are employees of Elekta Instrument AB. Dr. Schlesinger received clinical or research support (includes equipment or material) for this study from Elekta Instrument $\mathrm{AB}$.

\section{Author Contributions}

Conception and design: Schlesinger, Nordström, Lundin, Sheehan. Acquisition of data: Schlesinger, Nordström, Lundin. Analysis and interpretation of data: Schlesinger, Nordström, Lundin, Sheehan. Drafting the article: Schlesinger. Critically revising the article: all authors. Reviewed submitted version of manuscript: all authors. Approved the final version of the manuscript on behalf of all authors: Schlesinger. Study supervision: Schlesinger.

\section{Supplemental Information \\ Previous Presentations}

This paper was presented at the 18th International Leksell Gamma Knife Society Meeting, Amsterdam, The Netherlands, May 15-19, 2016.

\section{Correspondence}

David J. Schlesinger, Department of Neurological Surgery, University of Virginia, Box 800212, Charlottesville, VA 22908. email: djs9c@virginia.edu. 